\section{Sport Physiotherapy Canada issue: change is in the air}

\author{
Christopher Napier (1) , 1,2,3 Paul Hunter ${ }^{2,4,5}$
}

\section{CHANGE IS IN THE AIR}

As the world has come to grip with the enormous upheavals over the last several months, we have all had to adjust to this new way of life (figure 1). For many in the sports medicine community, this has meant abandoning conferences and large sporting events, working from home and perhaps assisting on the front lines of this pandemic. While many of these changes have been abrupt, there have also been predictable changes going on in the background as we progress from one season to the next and from year to year.

Fresh from our 2020 Annual Members Meeting, which was held online from home with record attendance-perhaps there are some upsides to some of these changes-Sport Physiotherapy Canada (SPC) (@sportphysiocan) says goodbye to some of our executive committee as we welcome new members. Notably, Kim Lee-Knight, our Chairperson for the last 2 years, moves on to the position of pastChair and I (Paul Hunter) have stepped into the role of Chairperson for the next 2 years.

The last 2 years have been filled with many new opportunities and growth. The SPC credentialing syllabus has been completely overhauled and renewed to reflect current research and best practice. Our Sport Physiotherapy Diploma certification achieved the International Federation of Sports Physical Therapists (IFSPT) designation of 'Registered International Sports Physical Therapist (RISPT)' and our members now make up the second largest contingent of RISPT-holders worldwide.

Since the Second World Congress of Sports Physical Therapy in Belfast, Ireland, in 2017, our relationship with the IFSPT has grown into new connections in the sports medicine community. This culminated in October 2019 with the

'Department of Physical Therapy, The University of British Columbia, Vancouver, British Columbia, Canada ${ }^{2}$ Sport Physiotherapy Canada, Ottawa, Ontario, Canada ${ }^{3}$ Schools of Mechatronic Systems Engineering and Engineering Science, Simon Fraser University, Metro Vancouver, BC, Canada

${ }^{4}$ Marda Loop Physiotherapy, Calgary, Canada

${ }^{5}$ Canadian Sport Institute, Calgary, Alberta, Canada

Correspondence to Dr Christopher Napier, Department of Physical Therapy, The University of British Columbia, Vancouver V6T 1Z4, British Columbia, Canada; chris.napier@ubc.ca

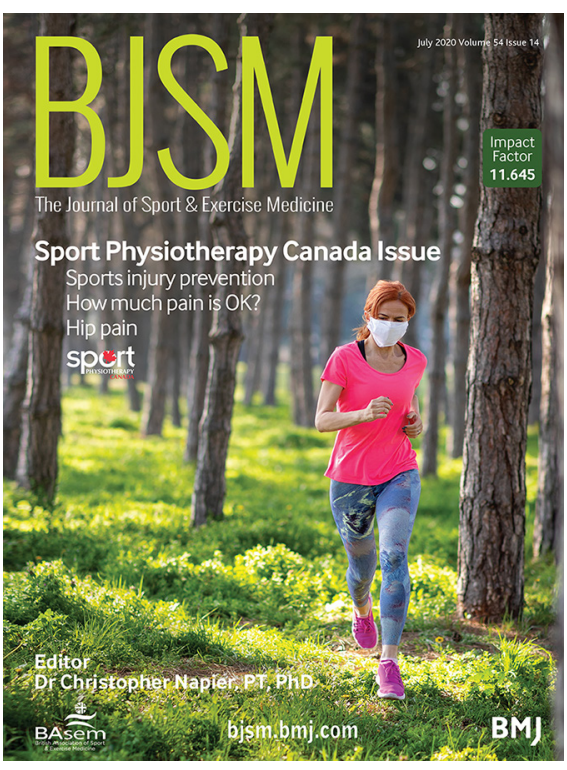

Figure 1 Symbolising 2020 and the COVID-19 pandemic: The Sport Physio Canada @SportPhysioCan issue of BJSM.

hugely successful Third World Congress of Sports Physical Therapy (\#SPC2019) in Vancouver, where our team met many of you. Hosted jointly by SPC and the IFSPT, this third edition of the biennial conference boasted a fantastic lineup of speakers and topics, with more than 550 attendees from 26 countries and 6 continents. Keep your eyes peeled for announcements about \#SPC2021! There has also been great success in the delivery of our annual Concussion Symposium (sold out as a preconference course at \#SPC2019). We have been committed to delivering a multidisciplinary learning symposium to showcase emerging research and treatment strategies for concussion management and this has been led by our own world-renown experts in the field of sports concussion (see page 866 for an example of clinically relevant research output from this group).

\section{WHAT LIES AHEAD?}

During the next 2 years, we plan to improve the Sport Physiotherapy education pathway by implementing new courses for physical therapists to obtain their Diploma in Sport Physiotherapy (and RISPT designation). We are also working alongside the Canadian Olympic Committee, National Sports Organisations and stakeholders to develop and implement a high performance certification programme for practitioners working with Canada's top athletes. The goal of this programme is to ensure a high standard for those working within elite sport and to develop, attract and retain exceptional sport practitioners in Canada. We look forward to continuing to work with our international colleagues to promote the RISPT designation and share ideas for the future.

\section{WHAT'S NEW IN THIS SPC ISSUE?}

If there is one thing that the lockdowns and closures of this pandemic have reaffirmed for sports medicine clinicians, it is that physical activity is as necessary as the air we breathe-it provides benefits to both physical and mental health, as well as a myriad of other important measures of society. While we are adjusting to a 'new normal' in work and school settings, Emma Norris (@ EJ_Norris) provides a timely systematic review of the importance of physical activity in elementary and preschool settings (see page 826). Spoiler alert: integrating physical activity into lessons at school increases physical activity and improves educational outcomes. Something to consider as we figure out novel ways to deliver education safely without sacrificing what's important.

While we may be without many professional and elite sports over the next while, that does not mean athletes are not still training and getting injured. Now, perhaps more than ever, understanding the different ways in which injury prevention programmes are implemented is helpful to determine the best mode of delivery depending on your current circumstances. Caroline Bolling (@CS_Bolling) offers a qualitative study on how injury prevention takes place in elite sport, as described by athletes, coaches and physiotherapists (see page 871). Keeping injury prevention as part of athletes' daily routines is key during this fallow period. Maintaining open communication-especially now-can help support injury prevention strategies during this time of increased training and decreased competition. Speaking of injury prevention, this issue features some Canadian content from the Sport Injury Prevention Research Centre at the University of Calgary. Brent Hagel (@BHagel4) addressed the question 'Do mouthguards reduce the odds of 


\section{Warm up}

sustaining a concussion among youth ice hockey players?' (see page 866 ) Read on to find the answer.

Don't miss the Consensus Statement from the 2018 International Hip-related Pain Research Network meeting in Zurich (see page 848). Leaders in the field review the evidence on patient-reported outcome measures for hip-related pain and recommend future research directions. Related to this is the question that Ben Smith (@ benedsmith) poses in his editorial: how much pain is ok (see page 821)? Smith, along with Riel, Vicenzino and Littlewood, emphasise the need for researchers to report the level of pain during and after exercise in physiotherapy exercise randomised controlled trials.

There is much more inside this issue, (figure 1) so sit back and read on! Stay safe and let's continue to work as a team to get through the coming months. The one constant we can count on is change. We hope to see you all again soon in-person (perhaps at \#SPC2021)!

Twitter Christopher Napier @runnerphysio

Funding The authors have not declared a specific grant for this research from any funding agency in the public, commercial or not-for-profit sectors.

Competing interests None declared.

Patient consent for publication Not required.
Provenance and peer review Commissioned: internally peer reviewed.

(c) Author(s) (or their employer(s)) 2020. No commercial re-use. See rights and permissions. Published by BMJ.

(A) Check for updates

To cite Napier C, Hunter P. Br J Sports Med 2020;54:819-820.

Accepted 8 May 2020

Br J Sports Med 2020;54:819-820. doi:10.1136/bjsports-2020-102636

ORCID iD

Christopher Napier http://orcid.org/0000-0002-14543546 